\title{
Tungiasis-related knowledge and treatment practices in two endemic communities in northeast Brazil
}

\author{
Benedikt Winter ${ }^{1}$, Fabíola A. Oliveira ${ }^{2}$, Thomas Wilcke ${ }^{1}$, Jorg Heukelbach ${ }^{2}$, Hermann Feldmeier $^{1}$ \\ ${ }^{1}$ Institute of Microbiology and Hygiene, Charité University Medicine, Berlin, Germany \\ ${ }^{2}$ Department of Community Health, School of Medicine, Federal University of Ceará, Brazil
}

\begin{abstract}
Background: Tungiasis, caused by the sand flea Tunga penetrans, is highly prevalent in many resource-poor communities in sub-Saharan Africa, Latin America and the Caribbean. Studies on knowledge and treatment practices related to tungiasis in affected populations are virtually nonexistent. To fill this gap, we performed a study in two resource-poor communities in northeast Brazil where this parasitic skin disease is highly prevalent.

Methodology: Structured interviews were realized in a representative sample of household leaders in an urban slum in Fortaleza, capital of Ceará State (northeast Brazil), and in a traditional fishing village $60 \mathrm{~km}$ southeast of the city.

Results: Two hundred ninety household leaders were interviewed in the urban slum and 136 in the fishing village. Knowledge about the etiological agent of tungiasis and its transmission was high in both communities: $90 \%$ knew the flea as the etiological agent of tungiasis. Transmission of tungiasis was thought to be related to sandy soil (72\% and $84 \%$ in the urban slum and in the fishing village, respectively), presence of animals (52\% and 59\%), walking barefoot (5\% and 23\%), and with the presence of garbage littering the area (23\% and $21 \%$ ). Surgical extraction of embedded sand fleas using unsterile sewing needles was the most commonly treatment applied (97\% and $96 \%$ ). In addition, a variety of topical products and medical ointments was used. Mothers were almost exclusively responsible for treatment and knowledge transfer to the next generation. The health sector neither provided health education nor treatment.

Conclusions: In communities of low socio-economic status in northeast Brazil, knowledge on tungiasis was high, but individuals did not follow appropriate treatment. A reduction of intensity of infestation, bacterial superinfection and associated morbidity is feasible with minimum support from the health sector, such as supplying hypodermic needles and disinfectants to mothers, and targeted health education.
\end{abstract}

Keywords: tungiasis, Tunga penetrans, parasitic skin disease, knowledge, practices

J Infect Dev Ctries 2009; 3(6):458-466.

Received 26 November 2008 - Accepted 7 June 2009

Copyright $\odot 2009$ Winter et al. This is an open-access article distributed under the Creative Commons Attribution License, which permits unrestricted use, distribution, and reproduction in any medium, provided the original work is properly cited.

\section{Introduction}

Tungiasis is a parasitic skin disease of many impoverished populations living in sub-Saharan Africa, the Caribbean and South America [1]. It occurs in urban slums, traditional fishing communities, and rural communities [2-6]. Prevalence and infestation intensity are particularly high in children 5-15 years of age and the elderly (Figure 1) [5,7]. If embedded sand fleas are not taken out appropriately, they may cause considerable morbidity [8]. Behavioural, social, and environmental risk factors have been identified, which may be targets for intervention to considerably reduce prevalence and intensity of the infestation [7,9].

However, a major prerequisite to obtain community support for control measures is to understand the knowledge and practices of the individuals affected. Studies on several parasitic diseases such as lymphatic filariasis and malaria have shown that ignorance and incorrect concepts about transmission, disease sequels, and treatment options may lead to negligence in prevention, reluctance in accepting treatment, and failure in the support of control measures [10-13]. It is therefore surprising that there are virtually no data on knowledge and health care behaviour of tungiasis-affected populations. To fill this gap, we performed a study on knowledge and practices in two resource-poor communities in northeast Brazil where this parasitic skin disease is highly prevalent, and compared data from urban and rural populations.

\section{Materials and Methods}

Study area and study populations

The study was conducted in the neighbourhood Vicente Pinzón II, a typical urban slum in Fortaleza, the capital of Ceará State in northeast Brazil, and in 
Figure 1. Cluster of tungiasis lesions on the fifth toe of a 2 year-old girl from the urban slum.

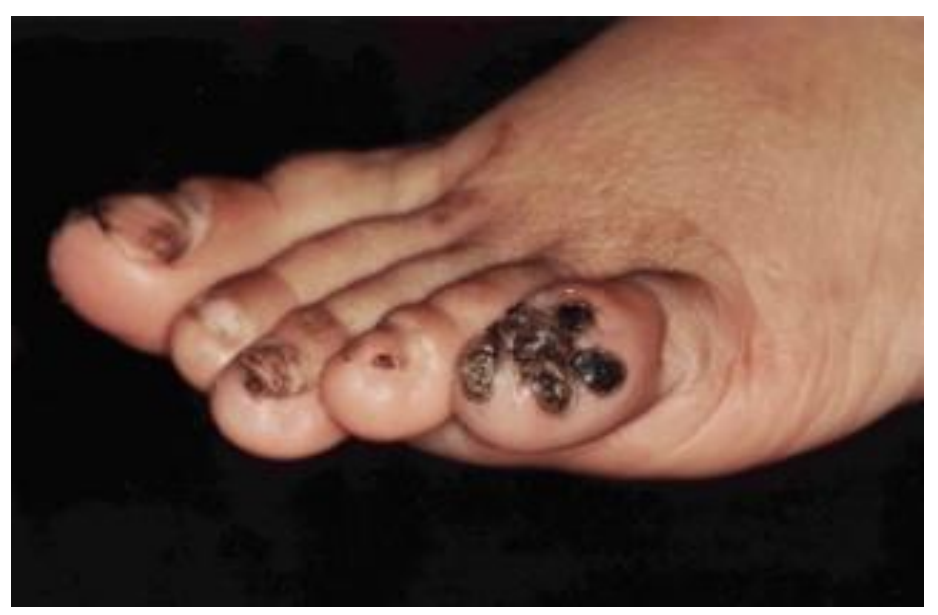

Balbino, a traditional fishing village on the coastline, situated $60 \mathrm{~km}$ southeast of Fortaleza.

Vicente Pinzón II was built on sand dunes close to the beach and has a total population of about 15,000 inhabitants. Two thirds of households have access to piped water. Sixty percent of the population have a monthly family income of less than two minimum wages ( 1 minimum wage $=€ 100$ at period of study). Adult illiteracy is about $30 \%$, and the unemployment rate is high [14]. Roads and paths are not paved. Waste collection is performed merely at the boundaries of the slum, and garbage of all sorts is scattered throughout the area. Hygienic conditions are precarious. The study area is comparable to the many other urban slums in Northeast Brazil.

In contrast to other villages along the coast, the people of Balbino have refused to sell land to real estate agencies, which would eventually have been divided up and sold to people from the capital and international tourists for weekend houses. Therefore, the village has remained largely unaffected by tourism and has conserved its traditional characteristics. Houses are located on relatively large compounds. There has been little fluctuation in the population over the last three decades, and many inhabitants have lived in the village since birth [4].

A cross-sectional study done in the same period in both communities has shown that the parasitic skin diseases tungiasis, scabies, pediculosis, and cutaneous larva migrans were common in both communities [4,15-17].

Prior to the present study, no control measures for parasitic skin diseases had ever been undertaken in the two communities. Simultaneously performed prevalence studies revealed a prevalence of tungiasis in the general population of $34 \%$ in the slum and $51 \%$ in the fishing village $[4,15]$. The proportion of tungiasis-affected individuals with heavy infestation was significantly higher in the fishing village as compared to the slum (8.2\% versus $3.5 \%)$.

Both communities were covered by the so-called Family Health Programme (Programa de Saúde da Família) which includes access to primary health care centres (PHC) for diagnosis and treatment and, if necessary, referral to a hospital or a more specialized service free of charge. The slum was served by a single PHC with five health care teams, each including a physician, a nurse, a nurse assistant, and five family health agents. Family health agents are usually recruited from the local population and are assigned to neighbourhoods with 85 to 250 households. The PHC serving the fishing community was situated in the village of Caponga, about $12 \mathrm{~km}$ away. In the fishing village, two family health agents were working, one responsible for the village in general, the other for the children.

In the urban slum, data of a recently performed census was used to select 300 households by random sampling, in order to obtain a representative sample of the population of the community. In the fishing village, all 140 households were included in the study.

\section{Study design}

As a first step, semi-structured interviews were performed with key informants (community leaders, traditional healers, community health agents). Based on the analysis of this information, a structured questionnaire was developed and pretested on eight individuals. The final questionnaire consisted of 10 questions on tungiasis, including knowledge on the etiological agent, its local designation and transmission. Knowledge of treatment, preventive practices, and disease-specific knowledge transfer was also surveyed.

All families of the target population were visited by the same field investigator (B.W.). Information was collected from household leaders. If these were absent, the households were revisited twice. If at the third occasion no interview could be performed, no further attempt was made to include the household in the survey.

\section{Ethical considerations}

The study was approved by the Ethical Review Board of the Federal University of Ceará. Interviews 
were performed only after informed consent by household leaders was obtained.

\section{Data entry and analysis}

Data were entered twice into a database using the Epi Info software package (version 6.04d, Centers for Disease Control and Prevention, USA), checked for entry errors, and analyzed using the respective Epi Info module. The chi squared test was used to determine significance of difference of relative frequencies.

\section{Results}

The demographic and parasitological characteristics of the study populations are summarized in Table 1. Of the 140 households of the fishing village and of the 300 households of the slum, information was obtained from $136(97.1 \%)$ and 290 $(96.6 \%)$, respectively.

\section{Etiological agent}

All household leaders were aware of tungiasis as a disease entity; in the fishing community 124 (91\%), and in the urban slum $278(96 \%)$ stated that they personally had experienced tungiasis at least once in their lifetime. In total, 261 (90\%) respondents attributed the disease to a penetrating flea, $17(6 \%)$ to an insect in general, and only 12 (4\%) did not know the cause of the disease.

$T$. penetrans was termed by many respondents as pulga de bicho ("flea of the beast") or pulga de pé ("flea of the foot"). People believed in a metamorphosis of the parasite: after penetration and hypertrophy, its designation changed to bicho de pé ("beast of the foot"). In fact, $133(46 \%)$ associated the transformation of the tiny flea into a skin lesion with a diameter of about $10 \mathrm{~mm}$ with a change in the morphology of the embedded parasite ("a pulga vira bicho" - "the flea transforms itself into a beast").

Only few informants used indigenous terms such as toim-toim or tupuru. The correct medical designation in Portuguese (tungíase) was totally unknown.

Of the respondents, 107 (37\%) from the urban slum and $76(56 \%)$ from the fishing village were sure that tungiasis would be caused by different flea species (Table 2). A black or a reddish colour of the central dot of the lesion - which corresponds to the final abdominal segments of the embedded flea [16] — was thought to be related to the most frequent variety of the ectoparasite. However, an embedded sand flea with a whitish colour was thought to cause the most severe type of tungiasis.

\section{Transmission}

The environmental determinants of tungiasis were well known by the respondents from the fishing village and from the urban slum: most participants associated the occurrence of $T$. penetrans with sandy soil $(72 \%$ and $84 \% ; \mathrm{p}<0.01)$ (Figure 2), and $5 \%$ and $23 \%$ mentioned walking barefoot as a reason for being affected by tungiasis ( $p<0.0001$ ), respectively.

The presence of animals was thought by $52 \%$ in the fishing village and $59 \%$ in the urban slum to contribute to the occurrence of disease $(p=0.13)$. Whereas dogs and cats were cited in both communities as the most important animals, rats were named only in the urban slum, and pigs only in the fishing village. The presence of garbage in the streets (21\% in the fishing village and $23 \%$ in the urban slum) as well as a lack of hygiene in the houses $(10 \%$ and $12 \%$, respectively) were also cited as factors associated with tungiasis.

Five $\%$ of household leaders in the urban slum and $12 \%$ in the fishing village were convinced that there was a causal relationship between the occurrence of $T$. penetrans and the blossoming of cashew trees around September $(p<0.01)$, although the vast majority of the respondents had no explanation how these two observations were linked. Some persons assumed that cashew flowers and fruits fallen on the ground would attract reservoir animals (pigs and dogs), which in turn would spread sand fleas. Others believed that the off-host-stage of T. penetrans would propagate better if the soil was littered with decaying cashew fruits.

\section{Treatment}

As a rule, tungiasis was treated by the affected individuals themselves or a family member $(96.8 \%$ in the urban slum and $100 \%$ in the fishing village) and not by health care professionals. Eleven percent of the respondents in the urban slum and $4 \%$ in the fishing village stated that they already sought medical assistance at the primary health care centre due to superinfection or other complications.

A variety of treatment practices were in use, surgical removal being most frequent (Figure 3). Hypodermic needles were rarely used to take out embedded fleas. In most cases attempts to extract embedded fleas were made with sewing needles, knives, thorns, tweezers, or pliers. People were well 
Table 1. Demographic and parasitological characteristics of the two study populations.

Fishing village

Number households (target population)

Complete data sets available

Gender of household leader

Male

Female

Household size (mean number of members, range)

Age in years (median, range)

Households with at least one case of tungiasis during the survey

Prevalence of tungiasis $(95 \% \mathrm{CI})[4,14]$

$$
\begin{aligned}
& 15(11.0 \%) \\
& 121(89.0 \%)
\end{aligned}
$$

$4.3(1-12)$

$19(0-86)$

$109(77.9 \%)$
Urban slum

300

$290(96.6 \%)$

$32(11.0 \%)$

$258(89.0 \%)$

$4.5(1-11)$

$14(0-86)$

$184(61.3 \%)$

$51.1 \%(47.0-55.5)$

$33.6 \%(30.9-36.4)$

Median number of lesions (range) $[4,14] \quad 2(1-145)$

Figure 2: Knowledge about environmental characteristics of tungiasis (urban slum $\mathrm{n}=290$, fishing village $\mathrm{n}=136$, multiple statements possible)

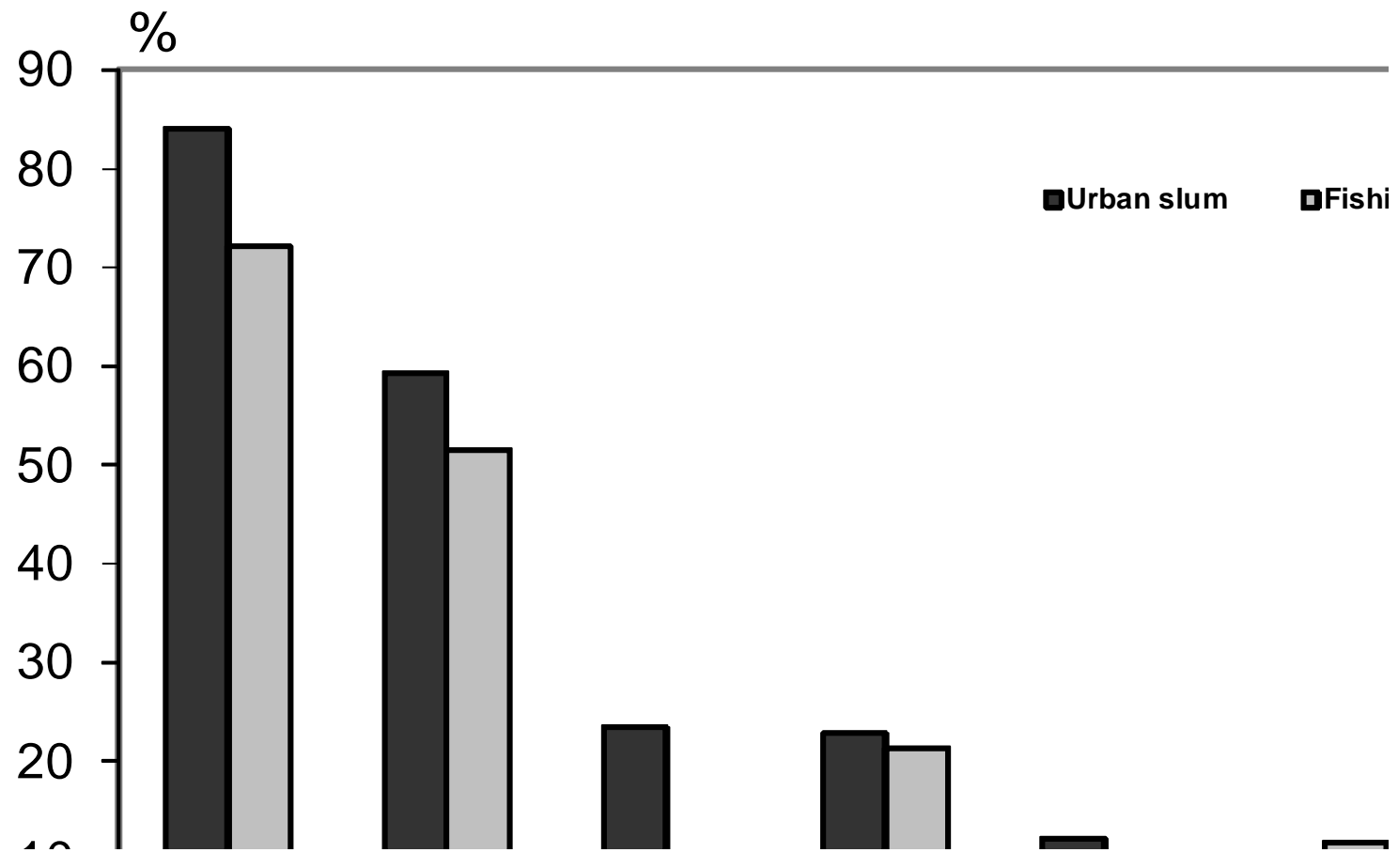


aware that the whole flea had to be extirpated to avoid severe inflammatory reactions $(98.6 \%$ of informants).

The following disinfectants were used in descending order of frequency: mercurochrome $(63 \%$ in the slum and $4 \%$ in the fishing village), ethanol (47\% and $10 \%)$, organic iodine (2\% and $3 \%)$, hydrogen peroxide (3\% and $0 \%$ ), ether ( $1 \%$ and $0 \%$ ) and potassium permanganate $(1 \%$ and $0 \%)$. Oily preparations and ointments were applied on the embedded sand fleas by $48(35 \%)$ of the families in the fishing village and by $99(34 \%)$ in the slum.

Vicks VapoRub ${ }^{\circledR}$ ointment (a topical compound consisting of menthol, camphor, eucalyptus oil and thymol in white vaseline) was used by $28 \%$ and $29 \%$ of the families, respectively. Other therapies were the application of olive oil, candle wax, coconut oil, cooking oil, cerumen, and various antibiotic and antimycotic ointments, alone or in combination with detergents such as washing powder. Insecticides such as pyrethroids, carbamates or transfluthrin, or kerosene had been applied on the lesions at least once by $25 \%$ of the informants.

Whereas disinfectants were preferred in the urban slum (42\% and 13\%; $\mathrm{p}<0.0001)$, in the fishing village a combination of castor oil with coconut oil was more commonly used ( $1 \%$ and $21 \%$; $\mathrm{p}<0.0001)$. Castor oil was extracted from the seed of the castor plant (Rhicinus communis) which grows abundantly in the area surrounding the fishing village.
Single respondents had peculiar misconceptions regarding actions to be undertaken together with the extirpation of the embedded flea. For example, one respondent stated, "After having taken out the flea, you must not wash your hands, because it may cause allergies or amputation of the fingers or toes" (female, 21 years, slum), while another claimed that "taking a shower after having taken out a flea causes tetanus" (female, 56 years, slum).

In both settings, treatment of children was mainly performed by mothers $(88 \%$ in the fishing village and $83 \%$ in the urban slum; $\mathrm{p}=0.25$ ). Rarely, other female family members (13\% and $9 \%$, respectively; $p$ $=0.3)$ or fathers $(14 \%$ and $9 \%$, respectively; $\mathrm{p}=$ 0.23 ) were responsible for extracting embedded sand fleas (Figure 4).

\section{Knowledge transfer}

In general, female family members were responsible for knowledge transfer to younger household members (Figure 5). Health agents, nurses, and physicians only marginally contributed to knowledge on this parasitic skin disease in both communities $(2.8 \%$ in the urban slum and $0.7 \%$ in the fishing village; $p=0.17$ ).

\section{Disease perception}

When asked to classify tungiasis into nuisance or disease, only 86 (29\%) of caretakers in the slum and $43(31 \%)$ in the fishing village considered tungiasis

Figure 3. Type of treatments applied (urban slum $n=280$, fishing village $n=136$, multiple statements possible).

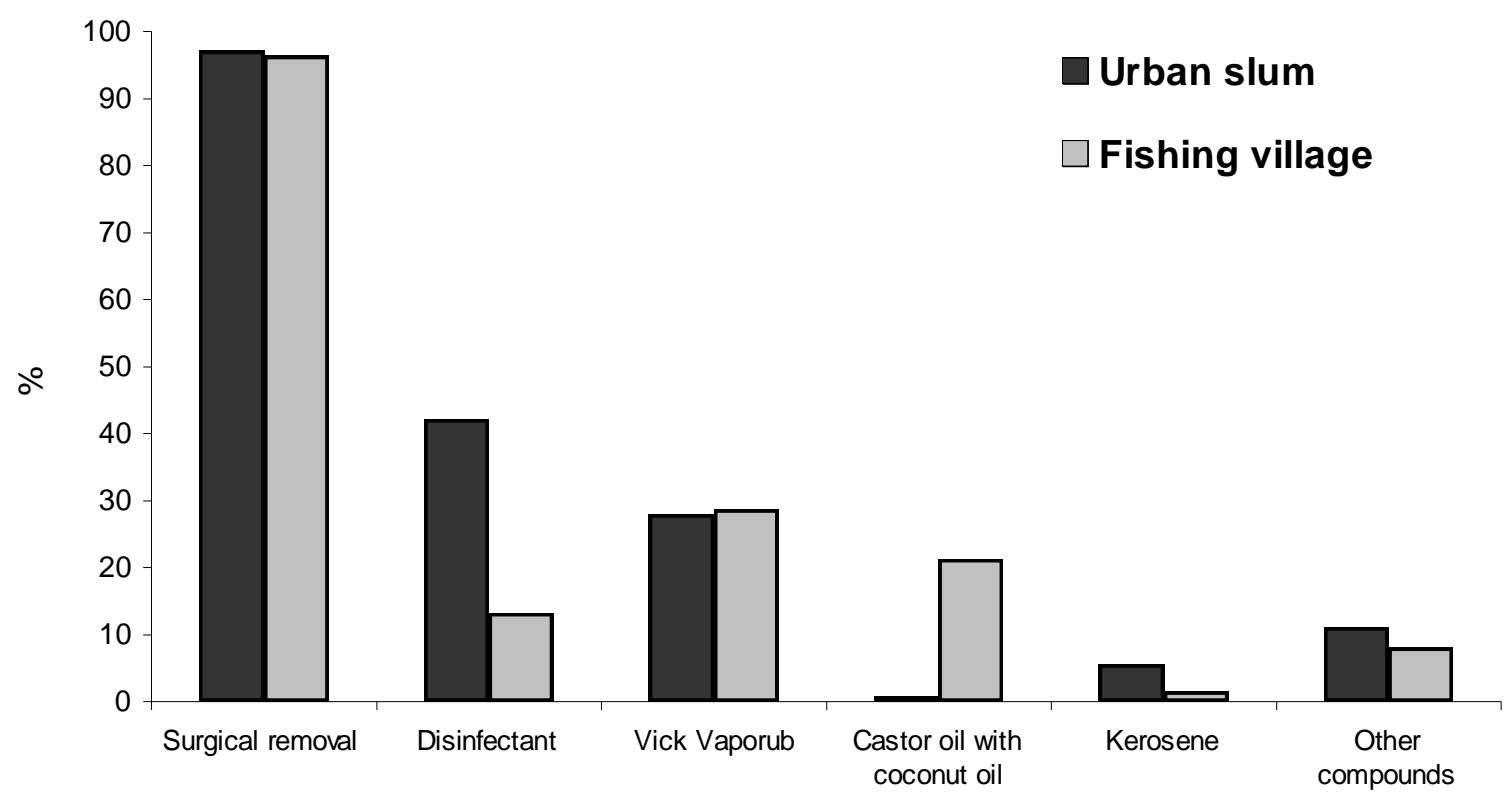


as a disease, whereas $69 \%$ in the urban slum and $68 \%$ in the fishing village considered the parasitic infestation as nuisance, being part of their normal life. However, $20 \%$ of respondents spontaneously mentioned that tungiasis may develop from a nuisance into a disease.

\section{Discussion}

Our study shows that in impoverished communities in northeast Brazil, knowledge on tungiasis was high, but individuals did not follow appropriate treatment.

Based on the assumption that knowledge and practices may differ according to social and economic characteristics [12], the study was performed in an urban slum (favela) and in an isolated fishing community. Prevalence and intensity of infestation was significantly higher in the fishing community $[4,15]$. In both communities, tungiasis was so prevalent, and the infestation was so high, that it has to be considered a public health threat. In fact, more than $90 \%$ of all families had experienced tungiasis at least once. Consequently, almost all respondents were sure that the disease was caused by a penetrating flea. A similarly high degree of knowledge on the infectious agent of a disease has been noted in populations suffering from malaria, schistosomiasis and filariasis, parasitic diseases with prevalences in endemic areas similar to tungiasis [10,18-20]. About half of informants were aware of the biological transformation through which a tiny free-running sand flea becomes a large embedded parasite and increases its volume by a factor of roughly 2000 [21].

Many informants were convinced that at least two different species of sand fleas exist, which could be differentiated by their colour and which differ somewhat in their capacity to cause inflammation and pain (Table 2). In fact, recent evidence indicates that in the area where this study was performed, at least two variants of $T$. penetrans occur that show a considerable degree of genetic heterogeneity [25]. Interestingly, recently a new pathogenic Tunga species (Tunga trimamillata) has been described from Ecuador [26]. It is possible that this that species also occurs in Brazil. Irrespective whether these

Figure 4. Transfer on disease-specific knowledge (multiple statements possible).

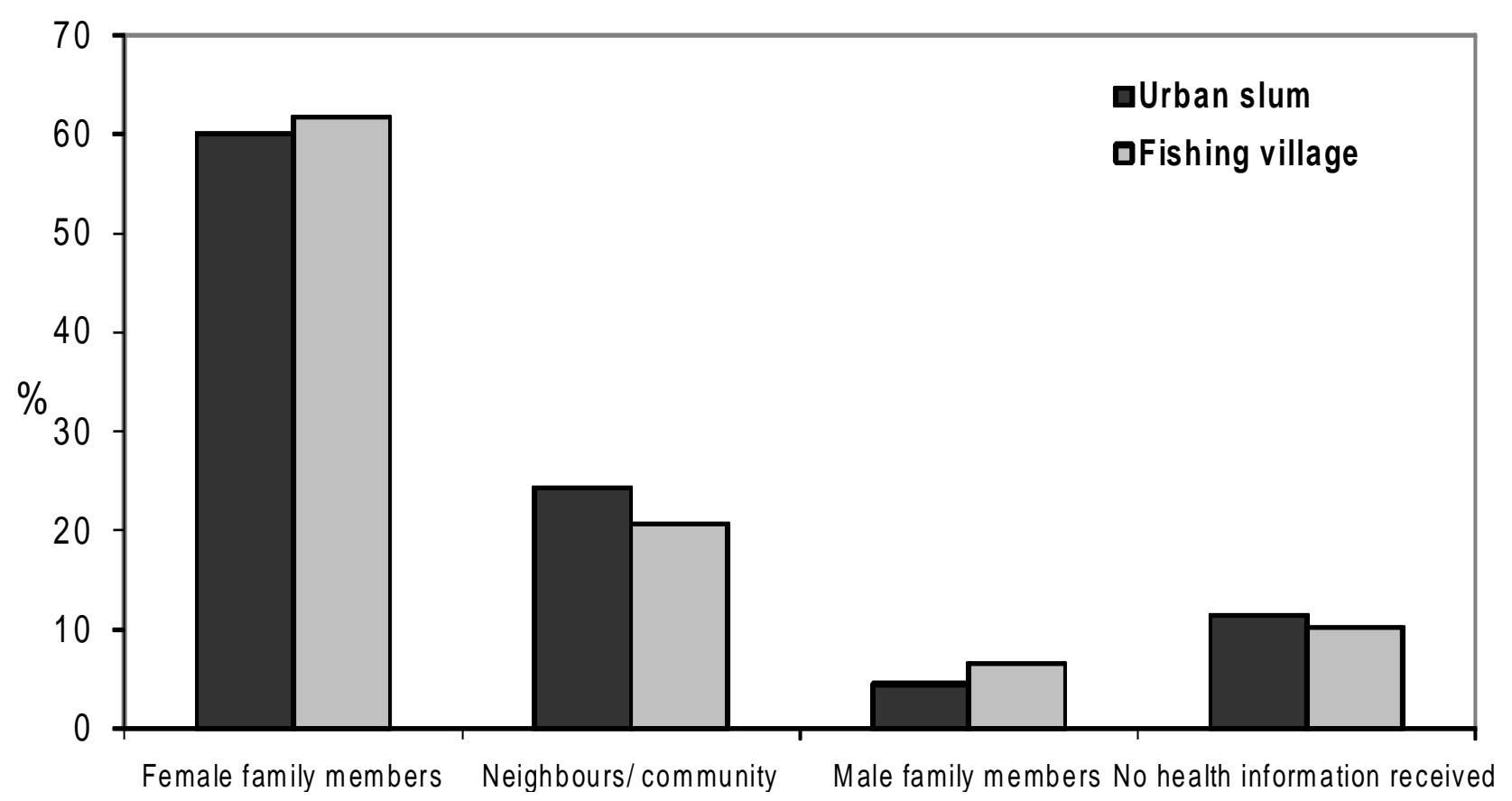


Figure 5. Household members responsible for treating children with tungiasis (multiple statements possible).

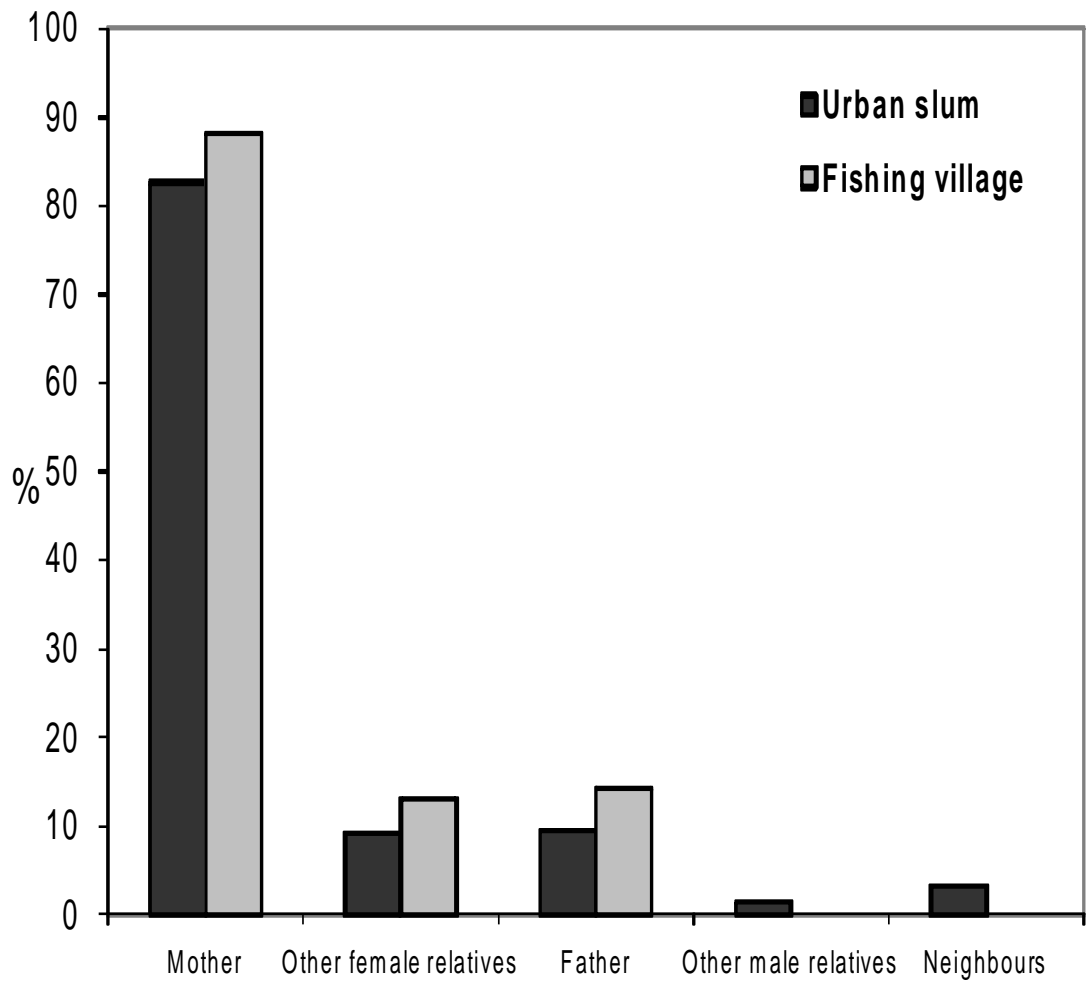

Table 2: Knowledge on the causal agent

\begin{tabular}{lll} 
& Fishing village & Urban slum \\
\hline $\begin{array}{l}\text { Tungiasis is caused by } \\
\text { one species }\end{array}$ & $59 / 136(43.4)$ & $171 / 290(59.0)$ \\
two species & $68 / 136(50.0)$ & $102 / 290(35.2)$ \\
three species & $8 / 136(5.9)^{\mathrm{a}}$ & $5 / 290(1.7)^{\mathrm{a}}$ \\
$\begin{array}{l}\text { Parasites have different } \\
\text { colors }\end{array}$ & & \\
Black & & \\
Reddish & $64 / 76(85.3)$ & $86 / 107(80.4)$ \\
Whitish & $66 / 76(88.0)$ & $85 / 107(79.4)$ \\
Other & $22 / 76(29.3)$ & $24 / 107(22.4)$ \\
The whitish lesion & $6 / 76(7.9)$ & $17 / 107(15.9)$ \\
Is more painful & $38 / 66(38.7)$ & $54 / 85(63.5)$ \\
$\quad \begin{array}{l}\text { Causes intense } \\
\text { inflammation }\end{array}$ & $1 / 66(0.6)$ & $9 / 85(10.6)$ \\
Is similar to others & $27 / 66(40.9)$ & $22 / 85(26.9)$ \\
$\begin{array}{l}\text { a1/136 and 12/290 individuals had no opinion regarding this issue } \\
\text { bof those individuals stating the existence of two or three species; multiple statements possible }\end{array}$
\end{tabular}

differences reflect differences in morphology or pathogenicity, it is an intriguing observation that individuals frequently suffering from tungiasis gained more knowledge on the parasite through personal experience than from entomologists through morphological studies on extracted sand fleas.
The environmental factors that favour the occurrence of tungiasis were well known in the affected communities. A recent risk factor study in the fishing village confirmed that the presence of sandy soil, domestic animals, and garbage littering the area contribute to the occurrence of tungiasis and severe infestation [7].

The discrepancy between the two settings in the notion that walking barefoot puts individuals at risk for tungiasis may be explained by the fact that, in the fishing village, almost everybody walks without shoes, and this behaviour is not discernible as a riskfactor by the inhabitants of this community. An opposite pattern was observed regarding the notion that cashew trees affect the occurrence of tungiasis (fishing community $12 \%$, urban slum 5\%). Tungiasis shows a highly characteristic pattern of seasonal variation with a peak in the middle of the dry season when cashew trees blossom [27]. There are no cashew trees in the surroundings of the urban slum, whereas these trees abound in the fishing village.

Almost all informants knew that embedded sand fleas can be extracted surgically and that the parasite has to be extirpated completely to avoid severe inflammation. However, in practice, this knowledge is not consistently applied. Appropriate medical 
instruments such as scalpels or sterile hypodermic needles are almost never at hand, and attempts to extract embedded fleas with sewing needles, nails or thorns may lead to bacterial infection [8]. It also requires a skilled hand and good eyesight to take out fleas completely, which cannot be done by children or the elderly. In addition, the surgical process is painful by itself, and children often resist attempts of a carer to take out an embedded flea (B. Winter unpublished observation). During the dry season, attack rates are so high that in an average family with three children, a mother would need about 20 to 30 minutes every evening to examine the feet of her children and to extract embedded sand fleas [28]. This situation explains how, despite knowledge on correct treatment practices, hundreds of lesions may accumulate in single individuals with consequently severe clinical pathology $[4,15,29]$.

The difficulties in surgical treatment of lesions also explain why topical remedies are commonly used. A great variety of substances was used, some of them (insecticides and used motor oil) potentially toxic. The broad spectrum of substances used topically may be taken as a hint that none of them is really effective. However, based on the information of some respondents that coconut oil is helpful in preventing the penetration of sand fleas, we undertook a study with a commercially available lotion containing coconut oil and jojoba oil, and found this lotion to be an effective repellent [30].

Knowledge on disease cause, transmission, and treatment practices was very similar in both settings. The few exceptions can be explained by behavioural or environmental particularities present in one setting, but absent in the other. For instance, rats act as a reservoir only in the urban slum, but not in the fishing community [22].

In conclusion, this study described knowledge and treatment practices of families living in two distinct tungiasis-affected communities. Disease knowledge was conveyed within the families with almost no input from the health sector. This confirmed our assumption that tungiasis is a disease wholly neglected by health care providers [1,31]. With minimal encouragement and support from the health sectors (e.g. by supplying skin disinfectant and hypodermic needles together with health education), embedded sand fleas could be removed at early stages of development by the affected individuals themselves, impeding severe morbidity.

\section{Acknowledgements}

We acknowledge the support of Vania Santos de Andrade Souza, the family health agents, and the inhabitants of Vicente Pinzón II and of Balbino village. The study was supported in part from the Ärzte für die Dritte Welt, Frankfurt, Germany. B. Winter, T. Wilcke and H. Feldmeier received travel grants from the DAAD/CAPES PROBRAL academic exchange programme. F.A.O. received a postdoctoral scholarship from CAPES. J. Heukelbach is research fellow from the Conselho Nacional de Desenvolvimento Científico e Tecnológico $(\mathrm{CNPq} / \mathrm{Brazil})$. The data of this study are part of a medical thesis by B. Winter.

\section{References}

1. Heukelbach J, Oliveira FA, Hesse G, Feldmeier H (2001) Tungiasis: a neglected health problem of poor communities. Trop Med Int Health 6: 267-272.

2. Carvalho RW, Almeida AB, Barbosa-Silva SC, Amorim M, Ribeiro PC, Serra-Freire NM (2003) The patterns of tungiasis in Araruama township, state of Rio de Janeiro, Brazil. Mem Inst Oswaldo Cruz. 98: 31-36.

3. Chadee DD (1998) Tungiasis among five communities in south-western Trinidad, West Indies. Ann Trop Med Parasitol 92: 107-113.

4. Muehlen M, Heukelbach J, Wilcke T, Winter B, Mehlhorn $\mathrm{H}$, Feldmeier H (2003) Investigations on the biology, epidemiology, pathology and control of Tunga penetrans in Brazil II. Prevalence, parasite load and topographic distribution of lesions in the population of a traditional fishing village. Parasitol Res 90: 449-455.

5. Nte AR, Eke FU (1995) Jigger infestation in children in a rural area of Rivers State of Nigeria. West Afr J Med 14: 5658.

6. Ugbomoiko US, Ofoezie IE, Heukelbach J (2007) Tungiasis: high prevalence, parasite load, and morbidity in a rural community in Lagos State, Nigeria. Int J Dermatol 46: 475-481.

7. Muehlen M, Feldmeier H, Wilcke T, Winter B, Heukelbach J (2005) Identifying risk factors for tungiasis and heavy infestation in a resource-poor community in Northeast Brazil. Trans R Soc Trop Med Hyg 100: 371-380.

8. Feldmeier H, Eisele M, Saboia-Moura RC, Heukelbach J (2003) Severe tungiasis in underprivileged communities: case series from Brazil. Emerg Infect Dis 9: 949-955.

9. Ugbomoiko US, Ariza L, Ofoezie IE, Heukelbach J (2007) Risk Factors for Tungiasis in Nigeria: Identification of Targets for Effective Intervention. PLoS Negl Trop Dis 1: 87.

10. Ruebush II TK, Weller SC, Klein RE (1992) Knowledge and beliefs about malaria on the pacific coastal plain of Guatemala. Am JTrop Med Hyg 46: 451-459.

11. Ahorlu CK, Dunyo SK, Asamoah G, Simonsen PE (2001) Consequences of hydrocele and the benefits of hydrocelectomy: a qualitative study in lymphatic filariasis endemic communities on the coast of Ghana. Acta Tropica 80: 215-221.

12. Gomes R, Mendonça EA, Pontes ML (2002) Social representations and the experience of illness. Cad Saúde Publica 18:1207-1214.

13. Ramaiah KD, Vijay Kumar KN, Ramu K (1996) Knowledge and beliefs about transmission, prevention and control of 
lymphatic filariasis in rural areas of South India. Trop Med Int Health 1: 433-438.

14. Family Health Program - Municipal Health Council of Fortaleza. UBASF Aída Santos e Silva. Relatório de territorialização. Fortaleza, 1999.

15. Wilcke T, Heukelbach J, Cesar Saboia MR, Kerr-Pontes RL, Feldmeier H (2002) High prevalence of tungiasis in a poor neighbourhood in Fortaleza, Northeast Brazil. Acta Trop 83: 255-258.

16. Heukelbach H, Wilcke T, Winter B, Feldmeier H (2005) Epidemiology and morbidity of scabies and pediculosis capitis in resource-poor communities in Brazil. British $\mathrm{J}$ Derm 153: 150-156.

17. Heukelbach H, Wilcke T, Feldmeier H (2004) Cutaneous larva migrans (creeping eruption) in an urban slum in northeast Brazil. Int J Derm 43: 511-515.

18. Ahlberg BM, Mwangi R, Poggensee G, Feldmeier H, Krantz I (2003) "Better infection than hunger". A study of illness perceptions with special focus on urinary schistosomiasis in Northern Tanzania. Afr Soc Rev 7: 18-34.

19. Ahorlu CK, Dunyo SK, Koram KA Nkrumah FK, AgaardHansen, J., Simonsen PE (1999) Lymphatic filariasis related perceptions and practices on the coast of Ghana: implications for prevention and control. Acta Trop 73: 251264.

20. Tarimo DS, Lwihual GK, Minjas JN, Bygbjerg IC (2000) Mothers' perception and knowledge on childhood malaria in the holendemic Kibaha district, Tanzania: implications for malaria control and the IMCI strategy. Trop Med Int Health 5: $179-184$.

21. Eisele M, Heukelbach J, van Marck E, Mehlhorn H, Meckes O, Franck S, Feldmeier H (2003) Investigations on the biology, epidemiology, pathology and control of Tunga penetrans in Brazil: I. Natural history of tungiasis in man. Parasitol Res 90: 87-99.

22. Heukelbach J, Costa AML, Wilcke T, Menke N, Feldmeier H (2004) The animal reservoir of Tunga penetrans in poor communities in northeast Brazil. Med Vet Entomol 18:329335 .

22. Ugbomoiko US, Ariza L, Heukelbach J (2008) Pigs are the most important animal reservoir for Tunga penetrans ( jigger flea) in rural Nigeria. Trop Doc 38: 226-227.

24. Linardi PM (2000) Família Tungidae. In Linardi PM, Guimaraes LR (eds) Sinfonápteros do Brasil, $1^{\text {st }}$ edn. Museu de Zoologia da Universidade de São Paulo, São Paulo, 4853.

25. Gamerschlag S, Mehlhorn H, Heukelbach J, Feldmeier H, D'Haese J (2008) Repetitive sequences in the ITS1 region of the ribosomal DNA of Tunga penetrans and other flea species (Insecta, Siphonaptera). Parasitol Res 102: 193-199.

26. Fioravanti ML, Pampiglione S, Trentini M (2003) A second species of Tunga (Insecta, Siphonaptera) infecting man: Tunga trimamilata. Parasite 10: 282-283.

27. Heukelbach J, Wilcke T, Harms G, Feldmeier H (2005) Seasonal variation of tungiasis in an endemic community. Am J Trop Med Hyg 72:145-149

28. Heukelbach J, Frank S, Feldmeier H (2003) High attack rate of Tunga penetrans (Linnaeus 1758) infestation in an impoverished Brazilian community. Trans R Soc Trop Med Hyg 98: 431-434.

29 Ariza L, Seidenschwang M, Buckendahl J, Gomide M, Feldmeier H, Heukelbach J (2007) Tungíase: doença negligenciada causando patologia grave em uma favela de Fortaleza, Ceará. Rev Soc Bras Med Trop 40: 63-67.

30. Feldmeier H, Kehr JD, Heukelbach J (2006) A plant-based repellent protects against Tunga penetrans infestation and sand flea disease. Acta trop 99: 126-136.

31. Heukelbach J, van Haeff E, Rump B,Wilcke T, Saboia Moura R, Feldmeier H (2003) Parasitic skin diseases: health care-seeking in a slum in north-east Brazil. Trop Med Int Health 4: 368-373.

\section{Corresponding Author}

Dr. Jorg Heukelbach

Departamento de Saúde Comunitária, Faculdade de Medicina Universidade Federal do Ceará

Rua Prof. Costa Mendes 1608, 5. andar

Fortaleza CE 60430-140, Brazil

Tel: ++55-85-33668045 Fax: ++55-85-33668050

Email: heukelbach@web.de

Conflict of interest: No conflict of interest is declared. 